Katayun Zierke

\title{
Die Steuerungswirkung der Darlegungs- und Beweislast im Verfahren vor dem Gerichtshof der Europäischen Union
}

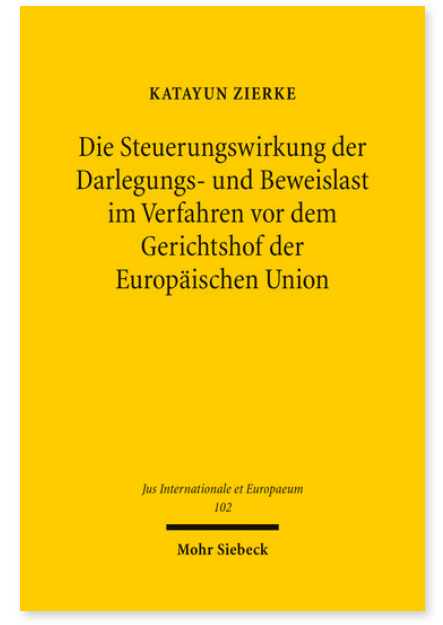

2015. XXV, 522 Seiten. JusIntEu 102

ISBN 978-3-16-153321-1

DOI 10.1628/978-3-16-153321-1

eBook PDF 104,00 €

ISBN 978-3-16-153296-2

fadengeheftete Broschur 104,00€
Die Darlegungs- und Beweislast hat im Verfahren vor dem Gerichtshof der Europäischen Union eine hohe praktische Bedeutung. Dennoch kennt das Unionsrecht nur sehr wenige Normen zum Beweisrecht. Dies gibt dem Gerichtshof die Möglichkeit, die Darlegungs- und Beweislastregeln selbst zu entwickeln und als Instrument zur Steuerung des Verfahrensausgangs einzusetzen. Anhand der Rechtsprechung des Gerichtshofs zu verschiedenen Bereichen des Binnenmarktrechts, etwa den Grundfreiheiten und dem Wettbewerbsrecht, untersucht Katayun Zierke die unterschiedlichen Facetten der Steuerungswirkung der Darlegungs- und Beweislast. Sie zeigt auf, dass diese zu einer Verzahnung der materiellen und prozessualen Ebene führt, die von den Parteien bei der Entwicklung einer Prozessstrategie berücksichtigt werden sollte. Diskutiert werden zudem Legitimationsansätze und -grenzen für die Steuerungswirkung.

Katayun Zierke Geboren 1984; Studium der Rechtswissenschaften an der Georg-August-Universität Göttingen und der Università di Bologna; Mitarbeiterin am Institut für Völker- und Europarecht der Georg-August-Universität Göttingen; 2009 Magister Legum Europae; 2014 Promotion; seit 2013 Rechtsreferendarin am Hanseatischen Oberlandesgericht Hamburg.

Jetzt bestellen:

https://mohrsiebeck.com/buch/die-steuerungswirkung-der-darlegungs-und-beweislast-im-verfahren-vor-dem-gerichtshofder-europaeischen-union-9783161533211?no_cache=1

order@mohrsiebeck.com

Telefon: +49 (0)7071-923-17

Telefax: $+49(0) 7071-51104$ 